\title{
Assessment of Current Gene Therapy Practices in Hepatocellular Carcinoma
}

\author{
Bryan Mckiver ${ }^{1}$, Mohamad Imad Damaj ${ }^{1}$ and Devanand Sarkar ${ }^{2, *} \mathbb{C}$ \\ 1 Department of Pharmacology and Toxicology, Massey Cancer Center, Virginia Commonwealth University, \\ Richmond, VA 23298, USA; mckiverbd@vcu.edu (B.M.); m.damaj@vcuhealth.org (M.I.D.) \\ 2 Department of Human and Molecular Genetics, Massey Cancer Center, VCU Institute of Molecular \\ Medicine (VIMM), Virginia Commonwealth University, Richmond, VA 23298, USA \\ * Correspondence: devanand.sarkar@vcuhealth.org; Tel.: +1-804-827-2339; Fax: +1-804-628-1176
}

Received: 29 September 2020; Accepted: 14 October 2020; Published: 10 December 2020

\begin{abstract}
Hepatocellular carcinoma (HCC) is the most common form of primary liver cancer and the fifth most common cancer worldwide. HCC is recognized as the fourth most common cause of cancer related deaths worldwide due to the lack of effective early diagnostic tools, which often leads to individuals going undiagnosed until the cancer has reached late stage development. The current FDA approved treatments for late stage HCC provide a minimal increase in patient survival and lack tumor specificity, resulting in toxic systemic side effects. Gene therapy techniques, such as chimeric antigen receptor (CAR)-T Cells, viral vectors, and nanoparticles, are being explored as novel treatment options in various genetic diseases. Pre-clinical studies using gene therapy to treat in vitro and in vivo models of HCC have demonstrated potential efficacy for use in human patients. This review highlights genetic targets, techniques, and current clinical trials in HCC utilizing gene therapy.
\end{abstract}

Keywords: HCC; gene therapy; clinical trials; CAR-T; viruses; nanoparticles; CRISPR/Cas9

\section{Introduction}

\subsection{Hepatocellular Carcinoma (HCC)}

HCC is characterized as the development of malignant tumors from liver hepatocytes and is the most common form of primary liver cancer and is the fourth most common leading cause of cancer related deaths worldwide, with nearly half a million new cases being diagnosed annually [1]. Common HCC risk factors include chronic Hepatitis B (HBV) and Hepatitis C (HCV) viral infections, alcoholism, and Non-alcoholic steatohepatitis (NASH) linked to obesity and diabetes [2]. An analysis of the Surveillance Epidemiology and End Results (SEER) registry indicated that the incidence rates of HCC have doubled from 1977 to 2007 in the US [3]. Currently, tyrosine kinase inhibitors (TKIs) sorafenib and lenvatinib are the only FDA approved first-line treatments for HCC, with TKIs regorafenib, cabozatinib, and tivantinib; immune checkpoint inhibitors nivolumab and pembrolizumab; and VEGF2R monoclonal antibody ramucirumab approved as second-line therapies [4]. These interventions induce severe negative side effects and only provide three month increases to overall survival in HCC patients. The development of more efficacious treatment strategies is critical to the survival and longevity of patients diagnosed with HCC.

\subsection{Gene Therapy}

Gene therapy is described as the experimental technique of using vectors to deliver exogenous genetic material into target cells that will alter gene expression by replacing missing or aberrant genes with the correct product, or inhibiting an existing gene product with the goal of alleviating a 
specific disease phenotype. The first successful application of gene therapy was in a clinical case study for a child diagnosed with severe combined immunodeficiency (SCID) in 1990 [5]. Since the time of this study, the field of gene therapy has seen substantial expansions in vector development and diversity, along with increased popularity in the clinic. Currently, only ex vivo gene therapies have been FDA approved to treat cancer, with Tisagenlecleucel (trade name: Kymriah) used to treat both lymphoblastic leukemia and diffuse large B-cell lymphoma (DLBCL) [6] and Axicabtagen ciloleucel (trade name: Yescarta) for DLBCL and Non-Hodgkins lymphoma [7]. Results from pre-clinical research studies applying gene therapy-based approaches to treat in vitro and in vivo models of HCC have demonstrated the therapeutic efficacy of these techniques, with some of them being incorporated into treatment regimens that are now in phase 2 and 3 clinical trials. The following sections detail gene therapy techniques that are currently being assessed in clinical trials for the treatment of HCC, as well as providing appropriate descriptions of pre-clinical data that supports their translation from bench to bedside.

\section{Gene Therapy Targets for HCC}

\subsection{Oncogenes}

Oncogenes have been described as genes that have the potential to induce carcinogenesis. In most cancer cells, these genes are mutated or overexpressed to significantly higher levels compared to normal healthy cells from similar tissues. Here, we provide a brief description of the most common oncogenes that have been demonstrated to be potential targets for gene therapy in HCC. Midkine (MDK), a heparin-binding growth factor, is within the top five overexpressed genes in human HCC and is used as a predictor of tumor metastasis [8]. Knock down of MDK increased sensitivity to anoikis and reduced cell survival in vitro and decreased tumor occurrence rate in vivo [9]. Yes associated protein (YAP), a transcriptional regulator, has higher expression in HCC cells in comparison to normal hepatocytes. YAP has been shown to promote tumor metastasis and mobilization via governing the cofilin/F-actin/lamellipodium axis by regulation of JNK/Bnip3/SERCA/CaMKII pathways [10]. Inhibition of YAP by siRNA encapsulated in a lipid nanoparticle resulted in marked regression of tumor in a genetically engineered mouse HCC model [11]. Survivin, a member of the inhibitor of apoptosis protein family, is another prognostic marker and has been shown to promote resistance to Tumor necrosis factor-related apoptosis-inducing ligand (TRAIL) treatment in HCC cells [12,13]. Treatment of HCC cells with surviving inhibitor YM155 induced cell cycle arrest and apoptosis and inhibited anchorage independent growth in vitro and inhibited the growth of patient-derived HCC xenografts in an orthotopic in vivo model [14]. Nanoparticle-delivered survivin siRNA inhibited HCC xenografts in mice and also improved survival in chemical carcinogen-induced HCC bearing mice [15]. B cell-specific Moloney murine leukemia virus integration site 1 (Bmi-1) is a polycomb ring finger oncogene that is upregulated in early stage HCC tumors. shRNA-mediated inhibition of Bmi-1 in HCC cell lines displayed reduced cell migration and invasion by upregulating phosphatase and the tensin homolog deleted on chromosome 10 (PTEN), inhibiting the phosphatidylinositol 3-kinase (PI3K)/Akt signaling pathway and downregulating the expression of matrix metalloproteinase (MMP)-2, MMP-9, and vascular endothelial growth factor (VEGF) [16]. Astrocyte Elevated Gene-1 (AEG-1) is an oncogene that has been observed to be overexpressed in all cancers, where it promotes proliferation, angiogenesis, invasion, migration, metastasis, and chemoresistance in tumor cells [17]. AEG-1 inhibition by hepatocyte-targeted nanoparticle-delivered siRNA significantly inhibited orthotopic human HCC xenografts in nude mice [18]. Notch homolog-1 (Notch-1) is a single pass transmembrane receptor involved in embryonic development. Overexpression of Notch-1 has shown potential as a predictor of poor prognosis and tumor metastasis in patients with HCC [19]. $\gamma$-secretase inhibitor-1 (GSI-1), an inhibitor of Notch-1 expression, combined with interleukin-24 (IL-24) was shown to reduce cell viability, decrease migration, and downregulate X-Linked Inhibitor of Apoptosis (XIAP), MMP-2, VEGF, SNAIL1, and SNAIL2 in HCC cells [20]. 


\subsection{Tumor Suppressor Genes}

Tumor suppressor genes typically function in the inhibition of cell proliferation and differentiation and the regulation of growth and development under normal conditions and are usually mutated or silenced during cancer development. Gene therapy techniques employ tumor suppressor genes, typically by using vectors to deliver transgene constructs that replenish functional gene products to combat tumor development. One of the most common tumor suppressor genes to be deleted or mutated in a variety of cancers, including HCC, is the TP53 gene. The p53 protein, generated from the TP53 gene, functions as a cell cycle regulator, with roles in DNA repair, cellular growth arrest, and apoptosis [21]. Adenovirus-mediated p53 delivery in combination with TACE demonstrated survival benefit in HCC patients in clinical trials [22]. Vestigial-Like Protein 4 (VGLL4) is transcriptional cofactor that functions as a tumor suppressor by directly binding YAP transcription factor, inhibiting the formation of the YAP-TEAD (Transcriptional Enhanced Associate Domain protein) transcription complex, leading to cell cycle arrest and promoted apoptosis in HCC tumor cells [23]. XIAP-Associated Factor-1 (XAF-1) is regarded as a tumor suppressor due to its ability to inhibit XIAP, reducing resistance to TRAIL in HCC cells [24]. Suppressors of Cytokine Signaling-1 (SOCS-1) has been shown to exhibit a tumor suppressor effect by inhibiting the phosphorylation of STAT3 and downregulating survivin expression in HCC cells [25]. Overexpression of Potassium voltage-gated Channel subfamily Q member 1 (KCNQ1) was shown to reduce the cellular invasion of HCC cells in vitro and diminished tumor metastasis in vivo by inhibiting the Wnt/ $\beta$-catenin signaling pathway [26]. Protocadherin9 (PCDH9) gene expression has been observed to be reduced in $22 \%$ of primary HCC tumors. Restoration of PCDH9 gene expression was shown to induce cell cycle arrest at G0/G1 in HCC cell lines in vitro and inhibit xenograft tumor formation in vivo [27]. Decreased expression levels of Vacuolar protein sorting-associated protein 4A (Vps4A) has been clinically associated with poorer prognosis and tumor progression in HCC. When Vps4A is overexpressed in HCC cells, it disrupts the uptake and secretion of miRNA from exosomes and inactivates PI3K/Akt signaling [28]. Overexpression of the cell-cell adhesion protein Catenin Alpha 3 (CTNNA3) inhibits cellular proliferation and reduces both migration and invasion, via inhibition of Akt signaling and MMP-9 activity, in HCC cell lines in vitro [29]. CCAAT/enhancer-binding protein alpha $(\mathrm{C} / \mathrm{EBP}-\alpha)$ is a leucine zipper transcription factor protein that is downregulated in several solid tumors, including HCC [30]. C/EBP- $\alpha$ is involved in liver homeostasis, enhancement myeloid-related gene expression, and regulates multiple cancer phenotypes such as proliferation, angiogenesis, and cell-cycle control [31]. In in vitro and in vivo models of HCC, small activating RNA (saRNA)-mediated restoration of $\mathrm{C} / \mathrm{EBP} \alpha$ resulted in the inhibition of epidermal growth factor receptor (EGFR)/ $\beta$-catenin signaling and the inhibition of tumor metastasis [32].

\subsection{Suicide Gene Therapy}

Suicide gene therapy involves the administration of an inactive prodrug and the delivery of a transgene encoding an enzyme that will metabolize the prodrug into cytotoxic metabolites, resulting in apoptosis of tumor cells. Suicide gene therapy is the most common method used for treating solid tumors. The most commonly used suicide gene therapy is the Herpes Simplex Virus Thymidine Kinase/Ganciclovir (HSVtk-GCV) system. Expression of the exogenous HSV enzyme initiates the conversion of the GCV prodrug into its cytotoxic metabolite GCV-triphosphate. GCV-triphosphate acts as a DNA chain terminator, with its incorporation resulting in cell death. The HSVtk-GCV suicide gene is typically used in combination with Liver Transplantation in the treatment of HCC. This approach showed partial efficacy in clinical trials [33]. Another suicide gene system used to treat HCC is Cytosine Deaminase (CD) and 5-Fluorocytosine (5-FC). Expression of the CD enzyme leads to the deamination of 5-FC, converting it into the cytotoxic drug 5-Flourouracil (5-FU), a Thymidylate Synthase (TS) inhibitor commonly used as a chemotherapeutic to treat HCC. HCC cell lines exposed to a double suicide gene system containing DNA encoding both TK and $\mathrm{CD}$, with subsequent administration of GCV/5-FC, displayed enhanced cell cycle arrest and apoptosis compared to HCC cells exposed to TK/GCV or CD/5-FC alone [34]. Additionally, suicide genes were under a VEGF 
promoter, ensuring that transgene expression and prodrug metabolism only occurred in cancerous cells as normal hepatocytes do not overexpress VEGF. The E. Coli derived enzyme Purine Nucleoside Phosphorylase (PNP) initiates the conversion of the prodrug Fludarabine Phosphate (FP) into the cytotoxic drug 2-fluoroadenine-triphosphate. This drug is an analog of adenosine-triphosphate (ATP) and its incorporation during DNA and RNA synthesis inhibits these processes, resulting in cell death. One of the benefits of this particular suicide gene system is that human PNP cannot metabolize FP, meaning only transfected cells can produce the cytotoxic metabolite. Ultrasonic nanobubbles delivered PNP gene induced apoptosis in HCC cells when treated with fludarabine phosphate [35]. Unfortunately, there are some caveats associated with inadequate transgene incorporation into all tumor cells. However, in suicide gene therapy, these issues are resolved by the bystander effect, where cytotoxic metabolites generated in one cell can enter neighboring cells via cell-cell contact. This results in the complete eradication of tumor cells, even tumor cells that do not express the transgene.

\section{Gene Therapy Strategies for HCC}

\subsection{Chimeric Antigen Receptor (CAR)-T Cells}

One of the most common types of cancer gene targeting therapies used to treat HCC is CAR-T cell-mediated immunotherapy. This type of ex vivo gene therapy involves the extraction of patient $\mathrm{T}$ cells that are infected with a virus, delivering a transgene that causes these cells to express a chimeric antigen receptor (CAR). These receptors allow CAR-T cells to target specific genes known to be expressed by cancer cells. After CAR-T cells have been generated, they are then delivered back to the patients to target and destroy cancer cells that express the CAR specific antigen. CARs are typically composed of three segments, an extracellular antigen recognition domain, a transmembrane domain, and an intracellular signaling domain [36,37]. The intracellular signaling domains of CARs utilize both an activation and costimulatory signaling cascade, with the number of costimulatory molecules being used to separate CARs into three distinct generations. First generation (1G) CARs, which possess a single activation signaling domain and have been shown to have limited clinical activity $[38,39]$. Second $(2 \mathrm{G})$ and third generation (3G) CARs use one or two costimulatory signaling molecules, respectively, to enhance $T$ cell proliferation and maintain an anti-tumor effect [40]. Current clinical trials utilizing CAR-T cell therapy for HCC patients are geared towards targeting a wide variety of gene products. Glypican-3 (GPC-3) is the most common target for CAR-T cell therapy in HCC. The GPC-3 is a $70 \mathrm{kDa}$ heparan sulfate proteoglycan attached to the exocytoplasmic surface of the plasma membrane [41]. It is normally expressed in human embryos and some adult tissues, not including the liver, where it functions in signaling for cellular growth and differentiation. In HCC, GPC-3 overexpression has been associated with poor prognosis [42]. Currently, there are several clinical trials employing GPC-3 CAR-T cells to treat HCC [NCT03146234, NCT02905188, NCT03884751, NCT03980288, NCT02395250, NCT03198546, NCT02715362, NCT03130712, NCT04121273, NCT02959151], with two trials also using a combination of chemotherapeutics [NCT03084380, NCT03302403]. Mucin-1 (MUC-1) is a transmembrane protein, possessing a heavy O-linked glycosylation in its extracellular domain, which is normally expressed in glandular epithelial cells of the lungs, stomach, mammary glands, and prostate [43]. Overexpression of aberrantly glycosylated MUC-1 has been observed in liver tumor tissues and can be used as a clinical bio marker, detected by probing patient serum samples with Wisteria Floribunda Aggluntinin, for cholangiocarcinoma and HCC [44]. At this time, there is a single clinical trial using MUC-1 CAR-T cell therapy in HCC patients [NCT02587689]. Epithelial Cell Adhesion Molecule (EpCAM) is a transmembrane glycoprotein that functions in cell signaling, proliferation, differentiation, and migration [45]. EpCAM has been found to be expressed in epithelial cells and various cancer tumor tissues. It is not expressed by normal mature hepatocytes; however, it has been observed to be upregulated in HCC and is associated with both poorly differentiated tumor morphology and poor prognosis [46]. Two clinical trials testing EpCAM-CAR-T cell in HCC are currently underway [NCT03013712, NCT02729493]. Cluster of Differentiation 147 (CD147), a 70 kDa 
transmembrane glycoprotein, is upregulated in a variety of cancers including HCC, where it contributes to aberrant cellular proliferation, invasion, and alterations in glucose and fatty acid metabolism [47-49]. Higher levels of CD147 expression has been shown to correlate with poorer patient prognosis and survival [49]. Currently, there is a single clinical trial using CD147-CAR-T cells to treat patients with advanced HCC [NCT03993743]. Programed Death-Ligand 1 (PD-L1) is a $40 \mathrm{kDa}$ transmembrane protein involved in suppressing the adaptive immune response. When PD-L1 interacts with the PD-1 receptor on T cells, it inhibits T cell receptor-mediated activation of Interleukin-2 (IL-2) production, a cytokine involved in lymphocyte activation, and the proliferation T cells. Like many other cancers, PD-L1 is upregulated on HCC tumor cell surfaces, allowing these cells to avoid the tumor immune response [50]. High levels of PD-L1 have been used as a predictor of tumor recurrence, aggressiveness, and poor prognosis in patients with HCC [51-53]. There is a clinical trial underway aimed at treating early stage HCC patients without metastasis with c-Met/PD-L1 targeting CAR-T cells [NCT03672305]. Alpha-Fetoprotein (AFP) is a $70 \mathrm{kDa}$ glycoprotein that is commonly overexpressed in HCC and is one of the most used biomarkers for the disease. AFP alone is not an appropriate target for CAR-T cell therapy as it is a secreted protein and is expressed intracellularly. To overcome this issue, CARs have been engineered to specifically target the AFP-MHC complex and have shown to suppress tumor growth in liver cancer xenograft models in vivo [54]. Unfortunately, A clinical trial focused on targeting AFP in HCC via ET1402L1-CAR-T cells (NCT03349255) was recently terminated and there are currently no active clinical trials for AFP-CAR-T in HCC. Limitations associated with the use of CAR-T cells in treating solid tumors include issues with antigen affinity, cell survival time, and negative interactions with tumor microenvironment [55]. Side effects associated with CAR-T cell therapy fall under three main categories: on-target/on-tumor toxicity (cytokine releasing syndrome), on-target/off-tumor toxicity (target-miss effect), and off-target/off-tumor toxicity (off-target effects) [56].

\subsection{Viral Vectors}

Oncolytic viruses are defined as wild or genetically altered viruses that target tumor cells specifically for infection. This subsequent infection will result in the lysis of tumor cells while causing little to no damage to healthy tissues. Other gene therapy strategies involving viruses use them as vectors to deliver transgenic components that target and destroy tumor cells [57].

\subsubsection{Adenovirus}

Human adenoviruses are DNA viruses that belong to the genus Mastadenovirus [58]. The features of human adenoviruses that makes them optimal vectors include their capacity to infect non-dividing and dividing cells, a unique tropism which allows them to infect various types of human tissues, potent transgene expression, high transgene capacity, and they can be titered to high concentrations [59]. Furthermore, human adenovirus vectors lack the ability to integrate their DNA into a host cell genome, which prevents insertional mutagenesis and genomic irregularities from treatment [60]. Human serotype 5 adenovirus is the most common viral vector used in gene therapy. In normal cells infected by human adenoviruses, the viral protein E1B would inactive the p53 signaling pathway, which is used as a checkpoint to prevent virally infected cells from progressing to $S$ phase leading to apoptosis. Recombinant human adenoviruses (rhAdV) used in gene therapy lack the ability to replicate in normal healthy tissues, due to E1 (replication) and E3 (immune response evasion) viral genes being deleted during the manufacturing process [61]. This is beneficial in HCC treatment as the p53 gene is commonly mutated or deleted in tumor cells, allowing the virus to replicate, leading to tumor cell lysis $[62,63]$. Currently, there are three clinical trials utilizing a type $5 \mathrm{rhAdV}$, in combination with other established chemotherapeutic strategies, to treat HCC patients [NCT01869088, NCT03790059, NCT03780049]. There are also three clinical studies that use recombinant adenoviruses encoding a functional human p53 transgene (rAd-p53) in combination with Transarterial Chemoembolization (TACE) treatment for HCC [NCT02561546, NCT02509169, NCT02418988]. Another common gene therapy strategy that employs adenovirus vectors involves the delivery of transgenic suicide genes to tumor cells. There 
are currently three clinical trials aimed at exploring the therapeutic effects of an adenovirus vector which encodes for thymidine kinase (AdV-TK) in combination with GCV treatment for HCC patients who have undergone liver transplantation surgery [NCT02202564, NCT00300521, NCT03313596]. Additionally, a recently completed study sought to administer intratumoral injections of an adenovirus vector containing the HsV-TK suicide gene (TK99UN) to HCC patients [NCT00844623].

\subsubsection{Vaccinia Virus}

The vaccinia virus is a member of the Poxviridae family and contains a genome composed of linear double-stranded DNA. Pexastimogene devacirepvec, also known as JX-594 (Pexa-Vec), is a modified vaccinia virus (Wyeth strain) in which the viral thymidine kinase gene has been deleted and a transgene encoding human Granulocyte Macrophage Colony-Stimulating Factor (GM-CSF) is expressed. The JX-594 virus will selectively infect tumor cells as replication of the virus is dependent on elevated EGFR signaling and thymidine kinase activity, both of which are cancer cell hallmarks, leading to lysis of the tumor cells [64]. Additionally, the GM-CSF transgene stimulates an adaptive immune response that targets the infected tumor cells. JX-594 has also been shown to have antivascular effects due to its ability to infect tumor specific vascular endothelial cells [65]. In a phase 1 clinical trial [NCT00629759], 14 patients with primary or metastatic liver cancer were administered various doses of JX-594 to determine its maximum tolerated dose and therapeutic safety. The maximum tolerated dose for intratumoral administration of JX-594 was determined to be $10^{9} \mathrm{pfu}$. Phase 2 clinical trials employing JX-594 as a therapeutic agent for HCC have been completed and used various populations including Sorafenib naïve patients with advanced HCC [NCT01636284], advanced HCC patients who failed Sorafenib treatment [NCT01387555], and patients with unresectable primary HCC tumors [NCT01171651, NCT00554372]. A phase 3 study is currently underway with the primary outcome aimed at determining if intratumoral injections of JX-594 followed by Sorafenib increases survival compared to Sorafenib alone in patients with advanced HCC [NCT02562755].

\subsubsection{Lentivirus}

Lentivirus vectors used in gene therapy are modified from Human Immunodeficiency Virus-1 (HIV-1) and belong to the retroviridae family of viruses. The lentivirus genome is comprised of a single RNA that is reverse transcribed into double stranded DNA during genomic replication. The features of lentivirus that make it an ideal vector for gene therapy include its ability to infect dividing and non-dividing cells, low immunogenicity, $10 \mathrm{~kb}$ transgene capacity, high compatibility, and high transfection efficiency. Lentivirus vectors encoding short-hairpin RNA (shRNA) are the most used as they possess fewer biological limitations compared to small interfering RNA (siRNA) vectors [66]. Lentivirus vectors are primarily used in the clinic to deliver CAR transgene constructs to autologous $\mathrm{T}$ cells for CAR-T immunotherapy and in pre-clinical studies, lentivirus vectors are used to knock down genes HCC cell lines [67,68].

\subsection{Nanoparticles}

Nanoparticles (NP) are defined as small, solid particulates ranging in size from 1-100 nm, which have an anticancer agent either adsorbed on its surface, encapsulated within its core, or both [69]. Once NPs enter the bloodstream, they are taken up by cells via endocytosis of phagocytosis, where the encapsulated therapeutic agent is released, inducing a therapeutic effect on the cell. NP systems that have been developed extensively in the field of gene therapy comprise of nano-antioxidants, metallic NPs, ceramic NPs, magnetite NPs, and silica NPs. Additionally, dendrimers, albumin, micelles, liposomes, and polysaccharides; such as dextran, chitosan, and poly ( $\alpha$-hydroxy esters); are macromolecular NPs that have been developed for anticancer drug delivery [69]. The surface of NPs can be modified with specific targeting ligands, such as monoclonal antibodies, to enhance tissue targeting and therapeutic efficacy. However, NP surface modulation may increase the likelihood of a vector being subject to opsonin-mediated clearance. NPs generally have good biocompatibility and biodegradability. Limitations associated with NP treatment vary depending on factors such as chemical 
composition, surface modification, addition of functional groups, and environment. Unpredictable reactions interactions of NPs following administration include entry into capillary vessels, crossing of the blood brain barrier, accumulation-mediated tissue inflammation, and the initiation of hemolysis and blood clotting [70].

\section{Lipid Nanoparticles (LNPs)}

Liposomal vectors are a subclass of LNPs composed of lipids organized into a spherical bilayer structure. Following intravenous administration, LNP systems have been shown to accumulate into tumor tissues through small apertures in tumor vascular tissue, about $200 \mathrm{~nm}$ in diameter. This accumulation has been termed the "enhanced penetration and retention" (EPR) effect of LNPs. A published report from a phase 1 clinical trial showed that in patients with advanced HCC, intravenous administration of ALN-VSP, a LNP composed of kinesin spindle protein (KSP) siRNA and VEGF siRNA in a 1:1 ratio, was well tolerated and prolonged disease stabilization in participants with nodal and extensive liver metastasis [71]. Results from another phase 1 clinical study utilizing intravenous injections of an LNP, MTL-CEBPA, were recently published, detailing the safety profile and anticancer effect in a small sample of patients with advanced HCC [72]. MTL-CEBPA encapsulates CEBPA small activating RNA (saRNA), which upregulates the expression of the CEBPA gene. Further, 36 participants received MTL-CEBPA treatment at six varying doses $\left(28-160 \mathrm{mg} / \mathrm{m}^{2}\right)$ on three dosing schedules and $89.5 \%$ (34/36) of the participants completed the safety assessment phase to day 28 . Of the 24 participants with evaluable HCC that completed the MTL-CEBPA treatment, one patient displayed an objective tumor response and 12 patients (50\%) maintained a stable disease state. After cessation of MTL-CEBPA, seven participants received additional treatment with tyrosine kinase inhibitors (TKIs). Three patients displayed complete tumor response, one patient displayed partial tumor response, and two patients maintained stable disease states. Sarker et al. concluded that MTL-CEBPA displayed an acceptable safety profile and a potential synergistic effect with TKI treatment in HCC [NCT02716012].

\subsection{Clustered Regularly Interspaced Short Palindromic Repeats and Cas Associated Proteins (CRISPR/Cas9)}

The CRISPR/Cas9 system was first identified in the adaptive immune system of prokaryotes where it functions in the removal and destruction of foreign nucleic acid sequences [73]. Researchers have been able to manipulate this system and utilize it as tool for genome editing studies and clinical gene therapy. The CRISPR/Cas9 system is composed of the core components: the Cas9 nuclease which cleaves double stranded DNA, a guide RNA to guide the system to the target sequence, and the target DNA sequence [74]. The CRISPR/Cas9 system is highly versatile and can be used to delete endogenous sequences (knockout), insert exogenous sequences (knock-in), or substitute target genes with a desired sequence. The CRISPR/Cas9 system is currently being used in a clinical trial to knockout PD-1 receptors in autologous T cells extracted from HCC patients who will also be receiving TACE treatment [NCT04417764]. The study uses the CRISPR/Cas9 system as an ex vivo gene therapy tool. This is likely due to the possibility of off target effects associated with the CRISPR/Cas9 system, which could potentially result in mutagenesis and do more harm than good in patients.

\section{Conclusions}

Techniques in gene therapy have developed immensely over the last few decades in terms of vector development and identifying effective gene targets, thus facilitating transition of basic research findings to clinical trials. However, when it comes to the treatment of HCC, the implementation of gene therapy-based agents in a clinical setting is significantly lacking in comparison to that of other genetic diseases. Table 1 summarizes the status of the clinical trials discussed above and the gene therapy techniques used in each study to treat patients with HCC. Unlike the standard chemotherapies that are currently used to treat HCC, these gene therapies have been shown to specifically target tumor cells and have even been shown to enhance the efficacy of chemotherapeutics when used as a combination therapy strategy. Ongoing clinical research will pave the way for use of gene therapy strategies as the first line of therapy for HCC. 
Table 1. Data collected from clinicaltrails.gov as of 8.25 .2020 of clinical trials that use CAR-T cells, adenoviruses, JX-594 (Pexa-Vec), lipid nanoparticles, and CRISPR/Cas9 gene therapy to treat Hepatocellular carcinoma (HCC).

\begin{tabular}{|c|c|c|c|c|c|c|}
\hline $\begin{array}{l}\text { Clinical } \\
\text { Trials.gov } \\
\text { Identifier }\end{array}$ & $\begin{array}{l}\text { Study } \\
\text { Status }\end{array}$ & Intervention & $\begin{array}{c}\text { Route of } \\
\text { Administration }\end{array}$ & $\begin{array}{c}\text { Clinical } \\
\text { Trial Phase }\end{array}$ & Country & $\begin{array}{l}\text { Additional } \\
\text { Information }\end{array}$ \\
\hline NCT03146234 & Completed & GPC-3 CAR-T & Intravenous & N/A & China & - \\
\hline NCT02905188 & Recruiting & GPC-3 CAR-T & Intravenous & Phase 1 & USA & - \\
\hline NCT03884751 & Recruiting & GPC-3 CAR-T & Intravenous & Phase 1 & China & - \\
\hline NCT03980288 & Recruiting & GPC-3 CAR-T & Intravenous & Phase 1 & China & - \\
\hline NCT02395250 & Completed & GPC-3 CAR-T & N/A & Phase 1 & China & - \\
\hline NCT03198546 & Recruiting & GPC-3 CAR-T & N/A & Phase 1 & China & - \\
\hline NCT02715362 & Unknown & GPC-3 CAR-T & $\begin{array}{l}\text { Transcatheter } \\
\text { Arterial Infusion }\end{array}$ & Phase $1 / 2$ & China & - \\
\hline NCT03130712 & Unknown & GPC-3 CAR-T & Intratumoral & Phase $1 / 2$ & China & - \\
\hline NCT04121273 & Recruiting & GPC-3 CAR-T & N/A & Phase 1 & China & - \\
\hline NCT02959151 & Unknown & GPC-3 CAR-T & $\begin{array}{l}\text { Intratumoral } \\
\text { Injection }\end{array}$ & Phase 2 & China & - \\
\hline NCT03084380 & Unknown & GPC-3 CAR-T & Intravenous & Phase $1 / 2$ & China & TACE \\
\hline NCT03302403 & Recruiting & GPC-3 CAR-T & Intravenous & N/A & China & $\begin{array}{c}\text { Fludarabine \& } \\
\text { Cyclophosphamide }\end{array}$ \\
\hline NCT02587689 & Unknown & Anti-MUC1 CAR-T & N/A & Phase 1 & China & - \\
\hline NCT03013712 & Recruiting & EpCAM CAR-T & $\begin{array}{c}\text { Vascular } \\
\text { intervention }\end{array}$ & Phase 1 & China & - \\
\hline NCT02729493 & Unknown & EpCAM CAR-T & N/A & Phase 2 & China & - \\
\hline NCT03993743 & $\begin{array}{l}\text { Active, not } \\
\text { Recruiting }\end{array}$ & CD147-CAR-T & $\begin{array}{l}\text { Hepatic Artery } \\
\text { Infusion } \\
\end{array}$ & Phase 1 & China & - \\
\hline NCT03672305 & $\begin{array}{c}\text { Not } \\
\text { Recruiting }\end{array}$ & c-Met/PD-L1 CAR-T & Intravenous & Phase 1 & China & - \\
\hline NCT01869088 & Unknown & rhAdV type-5 & Arterial injection & Phase 3 & China & TACE \\
\hline NCT03790059 & Recruiting & rhAdV type- 5 & $\begin{array}{l}\text { Intraoperative } \\
\text { injection }\end{array}$ & N/A & China & RFA \\
\hline NCT03780049 & Recruiting & rhAdV type- 5 & $\begin{array}{l}\text { Hepatic artery } \\
\text { infusion }\end{array}$ & Phase 3 & China & HAIC \\
\hline NCT02561546 & Unknown & rAd-p53 & Arterial injection & Phase 2 & China & TACE \\
\hline NCT02509169 & Unknown & rAd-p53 & N/A & Phase 2 & China & TAE \\
\hline NCT02418988 & Unknown & rAd-p53 & Arterial injection & Phase 2 & china & TACE \\
\hline NCT02202564 & Completed & ADV-TK & Intraperitoneal & Phase 2 & China & Liver Transplant \\
\hline NCT00300521 & Completed & ADV-TK & N/A & Phase 2 & China & Liver Transplant \\
\hline NCT00844623 & Completed & $\begin{array}{c}\text { TK99UN (AdV with } \\
\text { HsV-TK) }\end{array}$ & Intratumoral & Phase 1 & Spain & N/A \\
\hline NCT03313596 & Recruiting & ADV-Tk & Intraperitoneal & Phase 3 & China & Liver Transplant \\
\hline NCT00629759 & Completed & JX-594 (Pexa-Vec) & $\begin{array}{c}\text { Transdermal } \\
\text { injection }\end{array}$ & Phase 1 & Korea & - \\
\hline NCT01636284 & Completed & JX-594 (Pexa-Vec) & Intravenous & Phase 2a & $\begin{array}{l}\text { USA and } \\
\text { Korea }\end{array}$ & - \\
\hline NCT01387555 & Completed & JX-594 (Pexa-Vec) & N/A & Phase $2 b$ & USA & - \\
\hline NCT01171651 & Completed & JX-594 (Pexa-Vec) & $\begin{array}{l}\text { Intravenous and } \\
\text { intratumoral }\end{array}$ & Phase 2 & Korea & sorafenib \\
\hline NCT00554372 & Completed & JX-594 (Pexa-Vec) & Intratumoral & Phase 2 & USA & - \\
\hline NCT02562755 & $\begin{array}{c}\text { Active, not } \\
\text { recruiting }\end{array}$ & JX-594 (Pexa-Vec) & Intratumoral & Phase 3 & USA & sorafenib \\
\hline NCT02716012 & Recruiting & MTL-CEBPA & Intravenous & Phase 1 & $\begin{array}{c}\text { Singapore, } \\
\text { Taiwan, and } \\
\text { UK }\end{array}$ & - \\
\hline NCT04417764 & Recruiting & $\begin{array}{l}\text { CRISPR/Cas9 PD-1 } \\
\text { KO T cells }\end{array}$ & $\begin{array}{l}\text { Percutaneous } \\
\text { Infusion }\end{array}$ & Phase 1 & China & TACE \\
\hline
\end{tabular}


Funding: The present study was supported in part by The National Institute of Diabetes and Digestive and Kidney Diseases (NIDDK) Grant 1R01DK107451-01A1; National Cancer Institute (NCI) Grants 1R01CA230561-01A1, 1R01CA240004-01, and 1R01CA244993-01; and Department of Defense (DOD) Grant CA170048.

Conflicts of Interest: The authors declare no conflict of interest.

\section{References}

1. Bray, F.; Ferlay, J.; Soerjomataram, I.; Siegel, R.L.; Torre, L.A.; Jemal, A. Global cancer statistics 2018: GLOBOCAN estimates of incidence and mortality worldwide for 36 cancers in 185 countries. CA Cancer J. Clin. 2018, 68, 394-424. [CrossRef] [PubMed]

2. Ghouri, Y.A.; Mian, I.; Rowe, J.H. Review of hepatocellular carcinoma: Epidemiology, etiology, and carcinogenesis. J. Carcinog. 2017, 16, 1. [PubMed]

3. El-Serag, H.B.; Mason, A.C. Rising incidence of hepatocellular carcinoma in the United States. N. Engl. J. Med. 1999, 340, 745-750. [CrossRef] [PubMed]

4. Johnston, M.P.; Khakoo, S.I. Immunotherapy for hepatocellular carcinoma: Current and future. World J. Gastroenterol. 2019, 25, 2977-2989. [CrossRef] [PubMed]

5. $\quad$ Blaese, R.M.; Culver, K.W.; Miller, A.D.; Carter, C.S.; Fleisher, T.; Clerici, M.; Shearer, G.; Chang, L.; Chiang, Y.; Tolstoshev, P.; et al. T lymphocyte-directed gene therapy for ADA-SCID: Initial trial results after 4 years. Science 1995, 270, 475-480. [CrossRef] [PubMed]

6. Tisagenlecleucel (Kymriah) for ALL. Available online: https://pubmed.ncbi.nlm.nih.gov/29039821/ (accessed on 28 September 2020).

7. Axicabtagene ciloleucel (Yescarta) for B-cell lymphoma. Available online: https://pubmed.ncbi.nlm.nih.gov/ 30036350/ (accessed on 28 September 2020).

8. Jia, H.L.; Ye, Q.H.; Qin, L.X.; Budhu, A.; Forgues, M.; Chen, Y.; Liu, Y.K.; Sun, H.C.; Wang, L.; Lu, H.Z.; et al. Gene expression profiling reveals potential biomarkers of human hepatocellular carcinoma. Clin. Cancer Res. 2007, 13, 1133-1139. [CrossRef]

9. Sun, B.; Hu, C.; Yang, Z.; Zhang, X.; Zhao, L.; Xiong, J.; Ma, J.; Chen, L.; Qian, H.; Luo, X.; et al. Midkine promotes hepatocellular carcinoma metastasis by elevating anoikis resistance of circulating tumor cells. Oncotarget 2017, 8, 32523-32535. [CrossRef]

10. Shi, C.; Cai, Y.; Li, Y.; Li, Y.; Hu, N.; Ma, S.; Hu, S.; Zhu, P.; Wang, W.; Zhou, H. Yap promotes hepatocellular carcinoma metastasis and mobilization via governing cofilin/F-actin/lamellipodium axis by regulation of JNK/Bnip3/SERCA/CaMKII pathways. Redox Biol. 2018, 14, 59-71. [CrossRef]

11. Fitamant, J.; Kottakis, F.; Benhamouche, S.; Tian, H.S.; Chuvin, N.; Parachoniak, C.A.; Nagle, J.M.; Perera, R.M.; Lapouge, M.; Deshpande, V.; et al. YAP Inhibition Restores Hepatocyte Differentiation in Advanced HCC, Leading to Tumor Regression. Cell Rep. 2015, 10, 1692-1707. [CrossRef]

12. Liu, J.L.; Zhang, X.J.; Zhang, Z.; Zhang, A.H.; Wang, W.; Dong, J.H. Meta-analysis: Prognostic value of survivin in patients with hepatocellular carcinoma. PLoS ONE 2013, 8, e83350. [CrossRef]

13. Namgung, Y.; Kim, S.Y.; Kim, I. Down-regulation of Survivin by BIX-01294 Pretreatment Overcomes Resistance of Hepatocellular Carcinoma Cells to TRAIL. Anticancer. Res. 2019, 39, 3571-3578. [CrossRef] [PubMed]

14. Xia, H.; Chen, J.; Shi, M.; Deivasigamani, A.; Ooi, L.L.; Hui, K.M. The over-expression of survivin enhances the chemotherapeutic efficacy of YM155 in human hepatocellular carcinoma. Oncotarget 2015, 6, 5990-6000. [CrossRef] [PubMed]

15. Khan, A.A.; Alanazi, A.M.; Jabeen, M.; Chauhan, A.; Ansari, M.A. Therapeutic potential of functionalized siRNA nanoparticles on regression of liver cancer in experimental mice. Sci. Rep. 2019, 9, 15825. [CrossRef] [PubMed]

16. Li, X.; Yang, Z.; Song, W.; Zhou, L.; Li, Q.; Tao, K.; Zhou, J.; Wang, X.; Zheng, Z.; You, N.; et al. Overexpression of Bmi-1 contributes to the invasion and metastasis of hepatocellular carcinoma by increasing the expression of matrix metalloproteinase (MMP)2, MMP-9 and vascular endothelial growth factor via the PTEN/PI3K/Akt pathway. Int. J. Oncol. 2013, 43, 793-802. [CrossRef] [PubMed]

17. Robertson, C.L.; Srivastava, J.; Rajasekaran, D.; Gredler, R.; Akiel, M.A.; Jariwala, N.; Siddiq, A.; Emdad, L.; Fisher, P.B.; Sarkar, D. The role of AEG-1 in the development of liver cancer. Hepatic Oncol. 2015, 2, 303-312. [CrossRef] 
18. Rajasekaran, D.; Srivastava, J.; Ebeid, K.; Gredler, R.; Akiel, M.; Jariwala, N.; Robertson, C.L.; Shen, X.N.; Siddiq, A.; Fisher, P.B.; et al. Combination of Nanoparticle-Delivered siRNA for Astrocyte Elevated Gene-1 (AEG-1) and All-trans Retinoic Acid (ATRA): An Effective Therapeutic Strategy for Hepatocellular Carcinoma (HCC). Bioconjugate Chem. 2015, 26, 1651-1661. [CrossRef] [PubMed]

19. Wu, T.; Jiao, M.; Jing, L.; Wang, M.C.; Sun, H.F.; Li, Q.; Bai, Y.Y.; Wei, Y.C.; Nan, K.J.; Guo, H. Prognostic value of Notch-1 expression in hepatocellular carcinoma: A meta-analysis. Onco Targets Ther. 2015, 8, 3105-3114. [CrossRef] [PubMed]

20. Han, B.; Liu, S.H.; Guo, W.D.; Zhang, B.; Wang, J.P.; Cao, Y.K.; Liu, J. Notch1 downregulation combined with interleukin-24 inhibits invasion and migration of hepatocellular carcinoma cells. World J. Gastroenterol. 2015, 21, 9727-9735. [CrossRef] [PubMed]

21. Zilfou, J.T.; Lowe, S.W. Tumor suppressive functions of p53. Cold Spring Harb. Perspect. Biol. 2009, 1, a001883. [CrossRef] [PubMed]

22. Guan, Y.S.; Liu, Y.; He, Q.; Li, X.; Yang, L.; Hu, Y.; La, Z. p53 gene therapy in combination with transcatheter arterial chemoembolization for HCC: One-year follow-up. World J. Gastroenterol. 2011, 17, 2143-2149. [CrossRef]

23. Xie, W.; Hao, J.; Zhang, K.; Fang, X.; Liu, X. Adenovirus armed with VGLL4 selectively kills hepatocellular carcinoma with G2/M phase arrest and apoptosis promotion. Biochem. Biophys. Res. Commun. 2018, 503, 2758-2763. [CrossRef] [PubMed]

24. Yamanaka, T.; Shiraki, K.; Sugimoto, K.; Ito, T.; Fujikawa, K.; Ito, M.; Takase, K.; Moriyama, M.; Nakano, T.; Suzuki, A. Chemotherapeutic agents augment TRAIL-induced apoptosis in human hepatocellular carcinoma cell lines. Hepatology 2000, 32, 482-490. [CrossRef] [PubMed]

25. Liu, L.; Li, W.; Wei, X.; Cui, Q.; Lou, W.; Wang, G.; Hu, X.; Qian, C. Potent antitumor activity of oncolytic adenovirus-mediated SOCS1 for hepatocellular carcinoma. Gene Ther. 2013, 20, 84-92. [CrossRef] [PubMed]

26. Fan, H.; Zhang, M.; Liu, W. Hypermethylated KCNQ1 acts as a tumor suppressor in hepatocellular carcinoma. Biochem. Biophys. Res. Commun. 2018, 503, 3100-3107. [CrossRef] [PubMed]

27. Lv, J.; Zhu, P.; Zhang, X.; Zhang, L.; Chen, X.; Lu, F.; Yu, Z.; Liu, S. PCDH9 acts as a tumor suppressor inducing tumor cell arrest at G0/G1 phase and is frequently methylated in hepatocellular carcinoma. Mol. Med. Rep. 2017, 16, 4475-4482. [CrossRef]

28. Wei, J.X.; Lv, L.H.; Wan, Y.L.; Cao, Y.; Li, G.L.; Lin, H.M.; Zhou, R.; Shang, C.Z.; Cao, J.; He, H.; et al. Vps4A functions as a tumor suppressor by regulating the secretion and uptake of exosomal microRNAs in human hepatoma cells. Hepatology 2015, 61, 1284-1294. [CrossRef]

29. He, B.; Li, T.; Guan, L.; Liu, F.E.; Chen, X.M.; Zhao, J.; Lin, S.; Liu, Z.Z.; Zhang, H.Q. CTNNA3 is a tumor suppressor in hepatocellular carcinomas and is inhibited by miR-425. Oncotarget 2016, 7, 8078-8089. [CrossRef]

30. Lourenco, A.R.; Coffer, P.J. A tumor suppressor role for C/EBPalpha in solid tumors: More than fat and blood. Oncogene 2017, 36, 5221-5230. [CrossRef]

31. Avellino, R.; Delwel, R. Expression and regulation of C/EBPalpha in normal myelopoiesis and in malignant transformation. Blood 2017, 129, 2083-2091. [CrossRef]

32. Huan, H.; Wen, X.; Chen, X.; Wu, L.; Liu, W.; Habib, N.A.; Bie, P.; Xia, F. C/EBPalpha Short-Activating RNA Suppresses Metastasis of Hepatocellular Carcinoma through Inhibiting EGFR/beta-Catenin Signaling Mediated EMT. PLoS ONE 2016, 11, e0153117. [CrossRef]

33. Sangro, B.; Mazzolini, G.; Ruiz, M.; Ruiz, J.; Quiroga, J.; Herrero, I.; Qian, C.; Benito, A.; Larrache, J.; Olague, C.; et al. A phase I clinical trial of thymidine kinase-based gene therapy in advanced hepatocellular carcinoma. Cancer Gene Ther. 2010, 17, 837-843. [CrossRef] [PubMed]

34. Li, J.; Zhou, P.; Li, L.; Zhang, Y.; Shao, Y.; Tang, L.; Tian, S. Effects of Cationic Microbubble Carrying CD/TK Double Suicide Gene and alphaVbeta3 Integrin Antibody in Human Hepatocellular Carcinoma HepG2 Cells. PLOS ONE 2016, 11, e0158592.

35. Zhang, B.; Chen, M.; Zhang, Y.; Chen, W.; Zhang, L.; Chen, L. An ultrasonic nanobubble-mediated PNP/fludarabine suicide gene system: A new approach for the treatment of hepatocellular carcinoma. PLoS ONE 2018, 13, e0196686. [CrossRef] [PubMed]

36. Cheadle, E.J.; Gornall, H.; Baldan, V.; Hanson, V.; Hawkins, R.E.; Gilham, D.E. CAR T cells: Driving the road from the laboratory to the clinic. Immunol. Rev. 2014, 257, 91-106. [CrossRef] [PubMed] 
37. Sadelain, M.; Brentjens, R.; Riviere, I. The basic principles of chimeric antigen receptor design. Cancer Discov. 2013, 3, 388-398. [CrossRef]

38. Till, B.G.; Jensen, M.C.; Wang, J.; Chen, E.Y.; Wood, B.L.; Greisman, H.A.; Qian, X.; James, S.E.; Raubitschek, A.; Forman, S.J.; et al. Adoptive immunotherapy for indolent non-Hodgkin lymphoma and mantle cell lymphoma using genetically modified autologous CD20-specific T cells. Blood 2008, 112, 2261-2271. [CrossRef] [PubMed]

39. Kershaw, M.H.; Westwood, J.A.; Parker, L.L.; Wang, G.; Eshhar, Z.; Mavroukakis, S.A.; White, D.E.; Wunderlich, J.R.; Canevari, S.; Rogers-Freezer, L.; et al. A phase I study on adoptive immunotherapy using gene-modified T cells for ovarian cancer. Clin. Cancer Res. 2006, 12, 6106-6115. [CrossRef]

40. Spear, T.T.; Nagato, K.; Nishimura, M.I. Strategies to genetically engineer T cells for cancer immunotherapy. Cancer Immunol. Immunother. 2016, 65, 631-649. [CrossRef]

41. Zhou, F.; Shang, W.; Yu, X.; Tian, J. Glypican-3: A promising biomarker for hepatocellular carcinoma diagnosis and treatment. Med. Res. Rev. 2018, 38, 741-767. [CrossRef]

42. Shirakawa, H.; Suzuki, H.; Shimomura, M.; Kojima, M.; Gotohda, N.; Takahashi, S.; Nakagohri, T.; Konishi, M.; Kobayashi, N.; Kinoshita, T.; et al. Glypican-3 expression is correlated with poor prognosis in hepatocellular carcinoma. Cancer Sci. 2009, 100, 1403-1407. [CrossRef]

43. Nath, S.; Mukherjee, P. MUC1: A multifaceted oncoprotein with a key role in cancer progression. Trends Mol. Med. 2014, 20, 332-342. [CrossRef] [PubMed]

44. Tamaki, N.; Kuno, A.; Matsuda, A.; Tsujikawa, H.; Yamazaki, K.; Yasui, Y.; Tsuchiya, K.; Nakanishi, H.; Itakura, J.; Korenaga, M.; et al. Serum Wisteria Floribunda Agglutinin-Positive Sialylated Mucin 1 as a Marker of Progenitor/Biliary Features in Hepatocellular Carcinoma. Sci. Rep. 2017, 7, 244. [CrossRef] [PubMed]

45. Patriarca, C.; Macchi, R.M.; Marschner, A.K.; Mellstedt, H. Epithelial cell adhesion molecule expression (CD326) in cancer: A short review. Cancer Treat. Rev. 2012, 38, 68-75. [CrossRef]

46. Terris, B.; Cavard, C.; Perret, C. EpCAM, a new marker for cancer stem cells in hepatocellular carcinoma. J. Hepatol. 2010, 52, 280-281. [CrossRef] [PubMed]

47. Huang, Q.; Li, J.; Xing, J.; Li, W.; Li, H.; Ke, X.; Zhang, J.; Ren, T.; Shang, Y.; Yang, H.; et al. CD147 promotes reprogramming of glucose metabolism and cell proliferation in HCC cells by inhibiting the p53-dependent signaling pathway. J. Hepatol. 2014, 61, 859-866. [CrossRef]

48. Li, J.; Huang, Q.; Long, X.; Zhang, J.; Huang, X.; Aa, J.; Yang, H.; Chen, Z.; Xing, J. CD147 reprograms fatty acid metabolism in hepatocellular carcinoma cells through Akt/mTOR/SREBP1c and P38/PPARalpha pathways. J. Hepatol. 2015, 63, 1378-1389. [CrossRef]

49. Lee, A.; Rode, A.; Nicoll, A.; Maczurek, A.E.; Lim, L.; Lim, S.; Angus, P.; Kronborg, I.; Arachchi, N.; Gorelik, A.; et al. Circulating CD147 predicts mortality in advanced hepatocellular carcinoma. J. Gastroenterol. Hepatol. 2016, 31, 459-466. [CrossRef]

50. Shi, F.; Shi, M.; Zeng, Z.; Qi, R.Z.; Liu, Z.W.; Zhang, J.Y.; Yang, Y.P.; Tien, P.; Wang, F.S. PD-1 and PD-L1 upregulation promotes $\mathrm{CD} 8(+) \mathrm{T}$-cell apoptosis and postoperative recurrence in hepatocellular carcinoma patients. Int. J. Cancer 2011, 128, 887-896. [CrossRef]

51. Gao, Q.; Wang, X.Y.; Qiu, S.J.; Yamato, I.; Sho, M.; Nakajima, Y.; Zhou, J.; Li, B.Z.; Shi, Y.H.; Xiao, Y.S.; et al. Overexpression of PD-L1 significantly associates with tumor aggressiveness and postoperative recurrence in human hepatocellular carcinoma. Clin. Cancer Res. 2009, 15, 971-979. [CrossRef]

52. Calderaro, J.; Rousseau, B.; Amaddeo, G.; Mercey, M.; Charpy, C.; Costentin, C.; Luciani, A.; Zafrani, E.S.; Laurent, A.; Azoulay, D.; et al. Programmed death ligand 1 expression in hepatocellular carcinoma: Relationship With clinical and pathological features. Hepatology 2016, 64, 2038-2046. [CrossRef]

53. Jung, H.I.; Jeong, D.; Ji, S.; Ahn, T.S.; Bae, S.H.; Chin, S.; Chung, J.C.; Kim, H.C.; Lee, M.S.; Baek, M.J. Overexpression of PD-L1 and PD-L2 Is Associated with Poor Prognosis in Patients with Hepatocellular Carcinoma. Cancer Res. Treat. 2017, 49, 246-254. [CrossRef] [PubMed]

54. Liu, H.; Xu, Y.; Xiang, J.; Long, L.; Green, S.; Yang, Z.; Zimdahl, B.; Lu, J.; Cheng, N.; Horan, L.H.; et al. Targeting Alpha-Fetoprotein (AFP)-MHC Complex with CAR T-Cell Therapy for Liver Cancer. Clin. Cancer Res. 2017, 23, 478-488. [CrossRef] [PubMed]

55. Wang, Z.; Guo, Y.; Han, W. Current status and perspectives of chimeric antigen receptor modified T cells for cancer treatment. Protein Cell 2017, 8, 896-925. [CrossRef] [PubMed]

56. Morgan, R.A.; Yang, J.C.; Kitano, M.; Dudley, M.E.; Laurencot, C.M.; Rosenberg, S.A. Case report of a serious adverse event following the administration of $\mathrm{T}$ cells transduced with a chimeric antigen receptor recognizing ERBB2. Mol. Ther. 2010, 18, 843-851. [CrossRef] [PubMed] 
57. Abudoureyimu, M.; Lai, Y.; Tian, C.; Wang, T.; Wang, R.; Chu, X. Oncolytic Adenovirus-A Nova for Gene-Targeted Oncolytic Viral Therapy in HCC. Front. Oncol. 2019, 9, 1182. [CrossRef]

58. Davison, A.J.; Benko, M.; Harrach, B. Genetic content and evolution of adenoviruses. J. Gen. Virol. 2003, 84, 2895-2908. [CrossRef]

59. Wang, Y.G.; Huang, P.P.; Zhang, R.; Ma, B.Y.; Zhou, X.M.; Sun, Y.F. Targeting adeno-associated virus and adenoviral gene therapy for hepatocellular carcinoma. World J. Gastroenterol. 2016, 22, 326-337. [CrossRef]

60. Hacein-Bey-Abina, S.; von Kalle, C.; Schmidt, M.; Le Deist, F.; Wulffraat, N.; McIntyre, E.; Radford, I.; Villeval, J.L.; Fraser, C.C.; Cavazzana-Calvo, M.; et al. A serious adverse event after successful gene therapy for X-linked severe combined immunodeficiency. N. Engl. J. Med. 2003, 348, 255-256. [CrossRef]

61. He, T.C.; Zhou, S.; da Costa, L.T.; Yu, J.; Kinzler, K.W.; Vogelstein, B. A simplified system for generating recombinant adenoviruses. Proc. Natl. Acad. Sci. USA 1998, 95, 2509-2514. [CrossRef]

62. Habib, N.A.; Mitry, R.R.; Sarraf, C.E.; Jiao, L.R.; Havlik, R.; Nicholls, J.; Jensen, S.L. Assessment of growth inhibition and morphological changes in in vitro and in vivo hepatocellular carcinoma models post treatment with dl1520 adenovirus. Cancer Gene Ther. 2002, 9, 414-420. [CrossRef]

63. Habib, N.; Salama, H.; Median, A.A.E.L.A.; Anis, I.I.; Al Aziz, R.A.A.; Sarraf, C.; Mitry, R.; Havlík, R.; Seth, P.; Hartwigsen, J.; et al. Clinical trial of E1B-deleted adenovirus (d11520) gene therapy for hepatocellular carcinoma. Cancer Gene Ther. 2002, 9, 254-259. [CrossRef] [PubMed]

64. Breitbach, C.J.; Bell, J.C.; Hwang, T.H.; Kirn, D.H.; Burke, J. The emerging therapeutic potential of the oncolytic immunotherapeutic Pexa-Vec (JX-594). Oncolytic Virother. 2015, 4, 25-31. [CrossRef] [PubMed]

65. Liu, T.C.; Hwang, T.; Park, B.H.; Bell, J.; Kirn, D.H. The targeted oncolytic poxvirus JX-594 demonstrates antitumoral, antivascular, and anti-HBV activities in patients with hepatocellular carcinoma. Mol. Ther. 2008, 16, 1637-1642. [CrossRef] [PubMed]

66. Huang, H.; Zhang, C.; Wang, B.; Wang, F.; Pei, B.; Cheng, C.; Yang, W.; Zhao, Z. Transduction with Lentiviral Vectors Altered the Expression Profile of Host MicroRNAs. J. Virol. 2018, 92, JVI.00503-18. [CrossRef] [PubMed]

67. Xie, S.; Wang, G.; Chen, G.; Zhu, M.; Lv, G. Lentivirus-mediated knockdown of P27RF-Rho inhibits hepatocellular carcinoma cell growth. Contemp. Oncol. (Pozn.) 2017, 21, 35-41. [CrossRef]

68. Kang, X.; Wang, F.; Lan, X.; Li, X.; Zheng, S.; Lv, Z.; Zhuang, Y.; Zhao, Y.; Zhou, S. Lentivirus-mediated shRNA Targeting CNN2 Inhibits Hepatocarcinoma in Vitro and in Vivo. Int. J. Med. Sci. 2018, 15, 69-76. [CrossRef]

69. Baig, B.; Halim, S.A.; Farrukh, A.; Greish, Y.; Amin, A. Current status of nanomaterial-based treatment for hepatocellular carcinoma. Biomed. Pharmacother. 2019, 116, 108852. [CrossRef]

70. Gordijn, B. Nanoethics: From utopian dreams and apocalyptic nightmares towards a more balanced view. Sci. Eng. Ethics 2005, 11, 521-533. [CrossRef]

71. Tabernero, J.; Shapiro, G.I.; LoRusso, P.M.; Cervantes, A.; Schwartz, G.K.; Weiss, G.J.; Paz-Ares, L.; Cho, D.C.; Infante, J.R.; Alsina, M.; et al. First-in-humans trial of an RNA interference therapeutic targeting VEGF and KSP in cancer patients with liver involvement. Cancer Discov. 2013, 3, 406-417. [CrossRef]

72. Sarker, D.; Plummer, R.; Meyer, T.; Sodergren, M.H.; Basu, B.; Chee, C.E.; Huang, K.W.; Palmer, D.H.; Ma, Y.T.; Evans, T.R.J.; et al. MTL-CEBPA, a Small Activating RNA Therapeutic Upregulating C/EBP-alpha, in Patients with Advanced Liver Cancer: A First-in-Human, Multicenter, Open-Label, Phase I Trial. Clin. Cancer Res. 2020, 26, 3936-3946. [CrossRef]

73. Marraffini, L.A.; Sontheimer, E.J. CRISPR interference: RNA-directed adaptive immunity in bacteria and archaea. Nat. Rev. Genet. 2010, 11, 181-190. [CrossRef] [PubMed]

74. Cong, L.; Ran, F.A.; Cox, D.; Lin, S.; Barretto, R.; Habib, N.; Hsu, P.D.; Wu, X.; Jiang, W.; Marraffini, L.A.; et al. Multiplex genome engineering using CRISPR/Cas systems. Science 2013, 339, 819-823. [CrossRef] [PubMed]

Publisher's Note: MDPI stays neutral with regard to jurisdictional claims in published maps and institutional affiliations. 